\title{
Catalytic Growth of Silicon Nanowires Assisted by Laser Ablation
}

\author{
Yi-Han Yang, Sheng-Jia Wu, Hui-Shan Chiu, Ping-I Lin, and Yit-Tsong Chen* \\ Department of Chemistry, National Taiwan University, Taipei 106, Taiwan, ROC, and Institute of \\ Atomic and Molecular Sciences, Academia Sinica, P.O. Box 23-166, Taipei 106, Taiwan, ROC
}

Received: May 28, 2003; In Final Form: October 23, 2003

\begin{abstract}
Silicon nanowires ( $\mathrm{SiNWs}$, diameter $\geq 5 \mathrm{~nm}$, and length $\sim \mu \mathrm{m}$ ) have been fabricated with metal- and $\mathrm{SiO}_{2^{-}}$ catalyses assisted by laser ablation. In the catalytic growth of single-crystalline SiNWs by pure metal catalysts $(\mathrm{Fe}, \mathrm{Ru}$, and $\mathrm{Pr}), \mathrm{Si}\{111\}$ is found to be the most stable plane and wire growth axis is along $\langle 111\rangle$. The growth mechanism follows a vapor-liquid-solid process, and the synthesized SiNWs typically have metaltips composed of metal and $\mathrm{Si}$, such as $\mathrm{FeSi}_{2}, \mathrm{RuSi}_{3}$, and $\mathrm{PrSi}_{4}$, respectively. In sharp contrast, a crystalline growth axis of $\langle 111\rangle$ and a wire growth axis of $\langle 112\rangle$ are the result in the SiNWs catalyzed by $\mathrm{SiO}_{2}$. Besides, the $\mathrm{SiO}_{2}$-catalytic SiNWs generally have no tips at the wire ends. Distinctive growth mechanisms resulting from metal- and $\mathrm{SiO}_{2}$-catalyses will be discussed. Pressure effect on the longitudinal and transverse growing rates in the fabrication of SiNWs has been examined.
\end{abstract}

\section{Introduction}

The optical and electrical properties of semiconductor-based nanostructures have recently stimulated tremendous research interest. A distinctive feature for semiconductor-based nanostructures relative to bulky material is the well-known quantum confinement effect owing to the reduced size and/or dimensionality. ${ }^{1-3}$ Silicon ( $\mathrm{Si}$ ) is an important semiconductor material with its contemporary microelectronic technology being one of the greatest successes for the past century. Nevertheless, there is still room for improvement in the applications of Si-based optoelectronic devices. For instance, $\mathrm{Si}$ is an indirect band-gap $(\sim 1.1 \mathrm{eV})$ material with a small exciton binding energy $(\sim 15$ $\mathrm{meV}$ ), and does not emit visible light. For this reason, a great deal of effort has been made lately to fabricate lower dimensional nanostructures, ${ }^{4-6}$ such as quantum wells, nanowires, and quantum dots, 2,3 in which the motion of charge carriers is confined, causing an increase of the band gap ${ }^{7}$ and/or a transformation of the electronic band structure from an indirect band gap to a direct one.

The advance of nanotechnology has led to a way to fabricate semiconductor materials from micro- to nanometers in size. Among other developments, more and more syntheses for onedimensional nanowires have been accomplished. For $\mathrm{Si}$, in particular, intensive research of one-dimensional nanowires and their corresponding optical and electrical properties has been done by several groups, such as Lee, ${ }^{8-20}$ Lieber, ${ }^{21-26}$ and Yu. ${ }^{12,13,27-37}$ In the research studies approached by these groups, the wirelike crystalline nanostructures of Si were often fabricated via vapor-liquid-solid (VLS) growth, ${ }^{38,39}$ in which a liquid cluster of metal-catalyst provides energetically favored sites for the absorption/adsorption of gas-phase reactants. The sizes of the catalysts are considered to be responsible for diameters of the resultant silicon nanowires (SiNWs). Based on this correspondence, the application of laser ablation to vaporize a target sample of bulky Si, mixed with metal catalyst, and to form small

* Author to whom all correspondence should be addressed at Institute of Atomic and Molecular Sciences, Academia Sinica, P.O. Box 23-166, Taipei 106, Taiwan. Fax: +886-2-2362-0200. E-mail: ytchen@pub.iams. sinica.edu.tw. sizes of nanoclusters in the initial VLS process is a unique and quite powerful method in the fabrication of one-dimensional SiNWs.

Different from the SiNWs catalyzed by metal nanoclusters via the VLS mechanism, another process for the nucleation and growth of $\mathrm{SiNWs}$, catalyzed by silicon dioxide $\left(\mathrm{SiO}_{2}\right)$, has been reported by Lee and co-workers in laser ablation ${ }^{8,12-16}$ as well as in thermal evaporation. ${ }^{9-10,17-20}$ In this work, we will investigate the catalytic roles of different metal catalysts (Fe, $\mathrm{Ru}, \mathrm{Pr}, \mathrm{RuCl}_{3}$, and $\mathrm{Pr}_{6} \mathrm{O}_{11}$ ) and $\mathrm{SiO}_{2}$ in the syntheses of SiNWs assisted by laser ablation. From these comparisons, we have tried to discern the growth mechanism via $\mathrm{SiO}_{2}$-catalysis from that via the VLS in traditional metal-catalytic processes. Differences in the crystalline and wire growth axes of SiNWs have been examined for the $\mathrm{SiO}_{2}$ - and metal-catalytic SiNWs.

\section{Experiment}

The apparatus used in our catalytic-growth experiments assisted by laser ablation is depicted in Figure 1. An evacuated alumina tube, placed inside a furnace, contains a target sample of Si powder (Acros, 325 mesh, 99+\%) and metal catalyst. We have used iron (Fe) powder (Prochem, 325 mesh, 99.9\%), ruthenium $(\mathrm{Ru})$ powder (Strem, 99.9\%), praseodymium (Pr) powder (Strem, 40 mesh, 99.9\% REO), ruthenium chloride $\left(\mathrm{RuCl}_{3}\right)$ powder (Strem, anhydrous, $\left.47.44 \% \mathrm{Ru}\right)$, and praseodymium oxide $\left(\mathrm{Pr}_{6} \mathrm{O}_{11}\right)$ powder (Strem, $\left.99.9 \% \mathrm{Pr}\right)$, respectively, as metal catalysts. Alternatively, $\mathrm{SiO}_{2}$ (Aldrich, 325 mesh, 99.6\%) was regarded as another supplying source for $\mathrm{Si}$, and had also been introduced in the target sample. Totally, we have carried out six experiments, including $\mathrm{Si}+\mathrm{Fe}, \mathrm{Si}+\mathrm{Ru}, \mathrm{Si}+$ $\mathrm{Pr}, \mathrm{Si}+\mathrm{SiO}_{2}+\mathrm{Fe}, \mathrm{Si}+\mathrm{SiO}_{2}+\mathrm{RuCl}_{3}$, and $\mathrm{Si}+\mathrm{SiO}_{2}+$ $\operatorname{Pr}_{6} \mathrm{O}_{11}$, respectively, as reacting ingredients. In the experiments without $\mathrm{SiO}_{2}$ in the target sample, Si powder and metal catalyst ( $\mathrm{Fe}, \mathrm{Pr}$, or $\mathrm{Ru}$ ) were mixed with a weight ratio of 90:10\%. When $\mathrm{SiO}_{2}$ was used in the growth of SiNWs, the weight ratio of $\mathrm{Si} / \mathrm{SiO}_{2} /$ metal compound $\left(\mathrm{Fe}, \mathrm{Pr}_{6} \mathrm{O}_{11}\right.$, or $\mathrm{RuCl}_{3}$ ) was typically 45:45:10\%

The sample mixture was pressed into a pellet, placed in a crucible/quartz holder, and located in the center of the alumina 


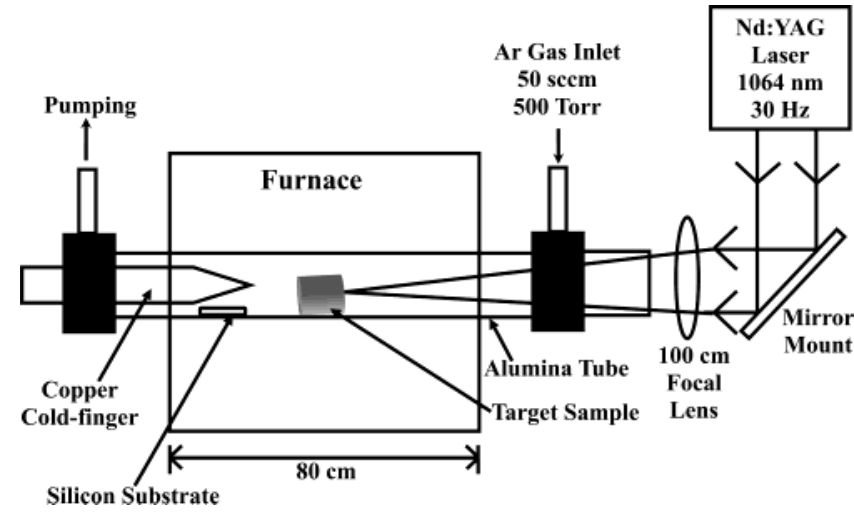

Figure 1. Apparatus for the catalytic-growth experiments of SiNWs assisted by laser ablation.

tube across the heating furnace (Figure 1). At one end of the alumina tube, an S1-UV window was attached for the pass of the laser beam; at the other, a water-cooling copper-finger and a Si-substrate were prepared for the collection of synthesized SiNWs. Before elevating the temperature, the alumina tube was evacuated, and then heated to $850^{\circ} \mathrm{C}$ for the tube-wall degassing for $2 \mathrm{~h}$. As such, impurities coated on the target sample can also be removed. After degassing, temperature was elevated gradually to reach a point depending on the catalyst used, e.g., a eutectic temperature of $\mathrm{FeSi}_{2}$ at $1207^{\circ} \mathrm{C}$ if $\mathrm{Fe}$ was employed as a catalyst, or $1212{ }^{\circ} \mathrm{C}$ when Pr was used. Argon (Ar) as a carrier gas with a typical total pressure of $\sim 500$ Torr and a flow rate of $50 \mathrm{sccm}$ was maintained throughout the experiment.

When the gas flow reaches steady, a pulsed Nd:YAG laser (Spectra Physics, GCR-190) with $1064 \mathrm{~nm}$ wavelength, $30 \mathrm{~Hz}$ repetition rate, and $\sim 70 \mathrm{~mJ} /$ pulse was ignited to ablate the target sample. The laser beam passing through a lens of $100-\mathrm{cm}$ focal length was confined into $1.5 \mathrm{~mm}$ in diameter on the target sample. A computer programmed alignment-control for the mirror-mount has been designed to guide the laser beam moving from one spot on the target sample to another during the ablation process. As such, the laser could ablate fresh sample-spots in the course of experiment. The reaction time ranges from a half to a few hours. Finally, a dark yellow-colored spongelike product was collected from the cold surface of the copper-finger, the $\mathrm{Si}$-substrate, and the inside wall of the alumina tube as well.

Morphologies of as-synthesized SiNWs have been taken from a scanning electron microscope (SEM) and a transmission electron microscope (TEM). The SEM morphologies of SiNWs were performed in (1) JEOL JSM-6300 SEM with Link EXL II EDX, (2) Hitachi S-800 Field Emission SEM, and (3) LEO 1530 Field Emission Gun SEM, and Energy Dispersive Spectrometer (FEG-SEM + EDS). The TEM images of SiNWs were carried out by JEOL JEM-1200EX II TEM at $80 \mathrm{kV}$ and Hitachi $\mathrm{H}-7100 \mathrm{TEM}$ at $75 \mathrm{kV}$. High-resolution transmission electron microscope (HRTEM) images of SiNWs were obtained by a Philips Tecnai F30 Field Emission Gun TEM (FEG-TEM) with an EDAX Energy Dispersive X-ray Spectrometer at $300 \mathrm{kV}$, JEOL JEM-2010 Analytical TEM at $200 \mathrm{kV}$, and JEOL JEM4000EX HRTEM at $400 \mathrm{kV}$.

\section{Results and Discussion}

3.1. Nanowire Synthesis. Catalyses by $\mathrm{Fe}$ and $\mathrm{SiO}_{2}$. In the fabrication of SiNWs using Fe as a catalyst, the target sample for laser ablation is composed of $\mathrm{Si} / \mathrm{Fe}=90: 10 \%$ (weight ratio). Alternatively, $\mathrm{SiO}_{2}$ was supposed to be another supplying source for $\mathrm{Si}$. We also used samples of $\mathrm{Si} / \mathrm{SiO}_{2} / \mathrm{Fe}=45: 45: 10 \%$ as reactants. The morphological contrasts in SEM, TEM, and

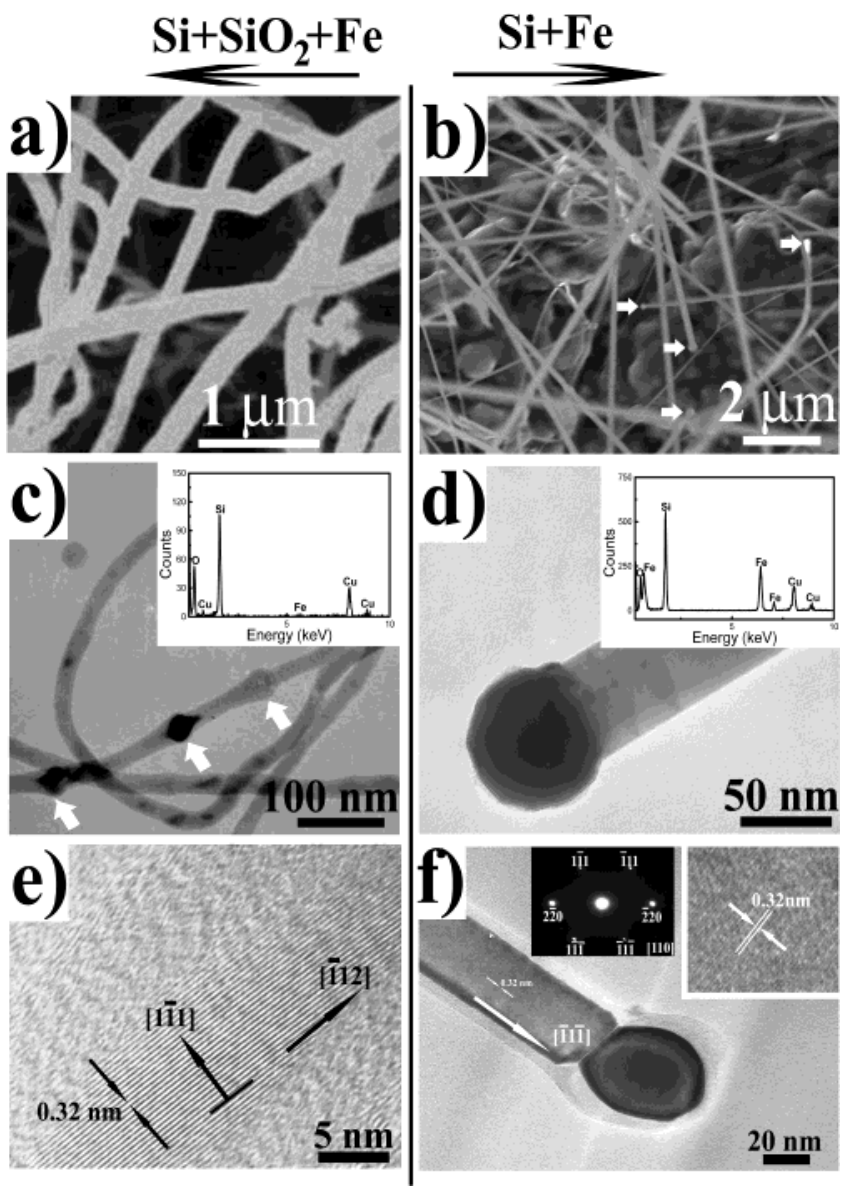

Figure 2. (a) SEM morphology of the SiNWs fabricated from $\mathrm{Si}+$ $\mathrm{SiO}_{2}+\mathrm{Fe}$, where the diameters of SiNWs range from 50 to $300 \mathrm{~nm}$ and the lengths are micrometers. (b) SEM morphology of the SiNWs catalyzed by $\mathrm{Fe}$ only, where the SiNWs are quite uniform. Parts of metal-tips at the SiNWs are marked by arrows. (c) TEM image for the $\mathrm{SiO}_{2}$-catalytic SiNWs of $\sim 25 \mathrm{~nm}$ diameter. The beadlike nanoparticles/ nanoclusters (marked by arrows) comprise $\mathrm{Si}, \mathrm{O}$, (molar ratio, $\mathrm{Si} / \mathrm{O}=$ 1:2), $\mathrm{Cu}$ (background of the $\mathrm{Cu}$ grid for TEM measurement), and a negligible amount of $\mathrm{Fe}$ as revealed by an EDS analysis (inset). (d) TEM image of an Fe-catalytic SiNW. The composition of the tip attached to the wire is $\mathrm{FeSi}_{2}$ as determined by EDS (inset). (e) HRTEM image shows the (111) crystalline plane with $d$-spacing of $0.32 \mathrm{~nm}$ in a $\mathrm{SiO}_{2}$-catalytic $\mathrm{SiNW}$. The [111] crystalline growth axis is perpendicular to the wire growth axis of [112]. The crystalline Si core and amorphous $\mathrm{SiO}_{x}$ sheath are also visualized. (f) HRTEM morphology for Fe-catalytic SiNW. From the ED pattern (upper-left inset) recorded along the [110] zone axis, the wire grows along the [111] direction and $(\overline{1} 1 \overline{1})$ lattice planes are of 0.32 -nm $d$-spacing (upper-right inset).

HRTEM between the SiNWs synthesized by $\mathrm{Si}+\mathrm{SiO}_{2}+\mathrm{Fe}$ and those by $\mathrm{Si}+\mathrm{Fe}$ are shown, respectively, in the left and right sides of Figure 2.

Figure 2a shows the SEM image of SiNWs resulting from the reaction of $\mathrm{Si}+\mathrm{SiO}_{2}+\mathrm{Fe}$ at 500 Torr of $\mathrm{Ar}$ carrier pressure, where the diameters of SiNWs range from 50 to 300 $\mathrm{nm}$ and the lengths are expressed in micrometers. By comparison, Fe-catalytic SiNWs fabricated without $\mathrm{SiO}_{2}$ in the target sample are shown in Figure 2b. Without $\mathrm{SiO}_{2}$, the synthesized SiNWs possess a sharper distribution in wire-diameter. Metaltips have also been found at the fabricated SiNWs, marked in part by arrows in Figure $2 \mathrm{~b}$, indicating a catalytic growth following the VLS mechanism.

TEM morphology in Figure 2c shows that the majority of the SiNWs, fabricated from $\mathrm{Si}+\mathrm{SiO}_{2}+\mathrm{Fe}$, contain bead(marked by arrows in Figure 2c) and wire-like nanostructures where the beadlike nanoparticles/nanoclusters are embedded in 
TABLE 1: Growth Direction, Composition, Crystallization, and Dimension of Catalytically Synthesized SiNWs

\begin{tabular}{|c|c|c|c|c|c|c|}
\hline & \multicolumn{6}{|c|}{ reacting ingredients } \\
\hline & $\mathrm{Si}+\mathrm{Fe}$ & $\mathrm{Si}+\mathrm{Ru}$ & $\mathrm{Si}+\mathrm{Pr}$ & $\mathrm{Si}+\mathrm{SiO}_{2}+\mathrm{Fe}^{a}$ & $\mathrm{Si}+\mathrm{SiO}_{2}+\mathrm{RuCl}_{3}{ }^{b}$ & $\mathrm{Si}+\mathrm{SiO}_{2}+\mathrm{Pr}_{6} \mathrm{O}_{11}{ }^{\mathrm{c}}$ \\
\hline crystalline growth axis & {$[\underline{1} 1 \overline{1}]$} & [1]1] & {$[\overline{1} 1 \overline{1}]$} & {$[1 \overline{1} 1]$} & {$[1 \overline{1} 1]$} & {$[1 \overline{1} 1]$} \\
\hline wire growth axis & {$[\overline{1} 1 \overline{1}]$} & [111] & {$[\overline{1} 1 \overline{1}]$} & {$[\overline{1} 12]$} & [1]12] & {$[\overline{1} 12]$} \\
\hline tip composition & $\mathrm{FeSi}_{2}$ & $\mathrm{RuSi}_{3}$ & $\mathrm{PrSi}_{4}$ & $\mathrm{SiO}_{\mathrm{x}}$ & $\mathrm{SiO}_{\mathrm{x}}$ & $\mathrm{SiO}_{\mathrm{x}}$ \\
\hline wire crystallization & single & single & single + poly & single & single & single \\
\hline Si core diameter & $\sim 36 \mathrm{~nm}$ & $\sim 5 \mathrm{~nm}$ & $\sim 16 \mathrm{~nm}$ & $\sim 8 \mathrm{~nm}$ & $\sim 5 \mathrm{~nm}$ & $\sim 15 \mathrm{~nm}$ \\
\hline $\mathrm{SiO}_{x}$ sheath thickness & $\sim 5 \mathrm{~nm}$ & $\sim 9 \mathrm{~nm}$ & $\sim 3 \mathrm{~nm}$ & $\sim 9 \mathrm{~nm}$ & $\sim 10 \mathrm{~nm}$ & $\sim 5 \mathrm{~nm}$ \\
\hline
\end{tabular}

${ }^{a}$ Ratio of 92:8\% is found for the fabricated $\mathrm{SiNWs}$ with [1111] crystalline growth axis and [112] wire growth axis catalyzed by $\mathrm{SiO}_{2}$ to those with $[\overline{1} 1 \overline{1}]$ crystalline growth axis and $[\overline{1} 1 \overline{1}]$ wire growth axis catalyzed by $\mathrm{Fe}$. This column represents the major product of $\mathrm{SiO}_{2}$-catalytic $\mathrm{SiNWs}$ ${ }^{b}$ Ratio of $92.3: 7.7 \%$ is found for the fabricated $\mathrm{SiNWs}$ with [111] crystalline growth axis and [112] wire growth axis catalyzed by $\mathrm{SiO}_{2}$ to those with [1 11$]$ crystalline growth axis and [111] wire growth axis catalyzed by $\mathrm{RuCl}_{3}$. This column represents the major product of $\mathrm{SiO}_{2}$-catalytic SiNWs. ${ }^{c}$ Ratio of 95.5:4.5\% is found for the fabricated $\mathrm{SiNWs}$ with [1 111 crystalline growth axis and [112] wire growth axis catalyzed by $\mathrm{SiO}_{2}$ to those with [ $\overline{1} 1 \overline{1}]$ crystalline growth axis and [111] wire growth axis catalyzed by $\operatorname{Pr}_{6} \mathrm{O}_{11}$. This column represents the major product of $\mathrm{SiO}_{2-}$ catalytic SiNWs.

the nanowires or bridging sequential wire-sections. To understand details about the growth mechanism, energy dispersive spectroscopy (EDS) was taken to analyze the chemical composition of the fabricated SiNWs. The inset of Figure $2 \mathrm{c}$ shows an EDS for the beadlike nanoparticles/nanoclusters, which comprise $\mathrm{Si}, \mathrm{O}$, (molar ratio, $\mathrm{Si} / \mathrm{O}=1: 2$ ), $\mathrm{Cu}$ (background of the $\mathrm{Cu}$ grid for TEM measurement), and a negligible amount of $\mathrm{Fe}$. The absence of $\mathrm{Fe}$ in the beadlike nanoparticles/ nanoclusters indicates that the growing is unlike a general process complying with an ordinary VLS mechanism, where metal-catalyst is often found to appear at the tip, root, or middle of synthesized nanowires. In sharp contrast, SiNWs synthesized from $\mathrm{Si}+\mathrm{Fe}$ have distinct Fe-head and Si-wire-body as shown in Figure 2d. An EDS analysis (inset of Figure 2d) reveals that the tip of the $\mathrm{SiNW}$ is mainly composed of $\mathrm{FeSi}_{2}$. This composition agrees very well with the phase diagram of $\mathrm{Si}-\mathrm{Fe}$ binary elements under the present experimental condition. In addition to the distinctive structures resulting from the presence/absence of $\mathrm{SiO}_{2}$, diverse morphologies such as belt-, whisker-, and fishbone-like nanostructures are also found in the Fe-catalytic SiNWs (not shown).

An HRTEM image gives the microstructures about the inner core and outer sheath of the SiNWs fabricated from $\mathrm{Si}+\mathrm{SiO}_{2}$ + Fe (Figure 2e), which depicts an outer sheath of $\sim 9 \mathrm{~nm}$ thickness and a crystalline core of $\sim 8 \mathrm{~nm}$ diameter. From the HRTEM image in Figure 2e, the crystalline growth axis of the SiNWs is along the [111] direction with $d$-spacing of $0.32 \mathrm{~nm}$. The wire growth axis directs to [112], which is determined by an electron diffraction (ED) measurement (not shown). The (111) crystalline planes of SiNWs are parallel to the [1112] wire growth axis, as can be seen in Figure 2e and tabulated in Table 1. It is noted that the majority $(92 \%)$ of the SiNWs fabricated from $\mathrm{Si}+\mathrm{SiO}_{2}+\mathrm{Fe}$ (weight ratio $=45: 45: 10 \%$ ) contain wire growth axis along [112] and the minority $(8 \%)$ of them orient at [11ㅣ (Table 1). On the other hand, wire growth axis of the SiNWs fabricated from $\mathrm{Si}+\mathrm{Fe}$ is all along [1111](Figure 2f), indicating that the $(\overline{1} 1 \overline{1})$ crystalline planes are perpendicular to the wire growth axis.

The distinctive wire growth axes of [ $\overline{1} 12]$ and [ $\overline{1} 1 \overline{1}]$ in the fabricated SiNWs (Figures 2e and 2f), respectively, from $\mathrm{Si}+$ $\mathrm{SiO}_{2}+\mathrm{Fe}$ and $\mathrm{Si}+\mathrm{Fe}$, indicate that different mechanisms have been followed with or without $\mathrm{SiO}_{2}$ in the reactant ingredients. In an earlier study by Lee and co-workers, ${ }^{8,9} \mathrm{SiO}_{2}$ was put forward as a catalyst, and the $\mathrm{SiO}_{2}$-containing reaction to fabricate SiNWs does not comply with an ordinary VLS mechanism. While the catalytic role of $\mathrm{SiO}_{2}$ will be discussed later in section 3.2, competition between $\mathrm{SiO}_{2}$ and $\mathrm{Fe}$ as catalysts in the fabrication of SiNWs has been observed in the present experiment. In the fabrication from $\mathrm{Si}+\mathrm{SiO}_{2}+\mathrm{Fe}$, the yield ratio of $92: 8 \%$ (Table 1) for the SiNWs of $\langle 112\rangle$ and $\langle 111\rangle$ wire growth axes resulting from the catalyses of $\mathrm{SiO}_{2}$ and $\mathrm{Fe}$, respectively, is out of proportion to the weight ratio of $\mathrm{SiO}_{2} / \mathrm{Fe}$ $=45: 10 \%$ in the initial target-sample. This abnormal product/ reactant ratio may suggest an easier reaction, either thermodynamically or kinetically, for $\mathrm{Si}+\mathrm{SiO}_{2}$ than for $\mathrm{Si}+\mathrm{Fe}$ in the fabrications of SiNWs.

Despite the different wire growth axes, the SiNWs catalyzed by pure $\mathrm{Fe}$ (Figure $2 \mathrm{f}$ ) have the same $\mathrm{Si}$-core and $\mathrm{SiO}_{x}$-sheath nanostructure as those catalyzed by $\mathrm{SiO}_{2}$ (Figure 2e). The oxygen could be due to the relatively low vacuum $(\sim 1$ mTorr $)$ in the reaction tube. The Fe-catalytic SiNW (Figure 2f) has a crystalline Si core of $\sim 36 \mathrm{~nm}$ in diameter and an amorphous $\mathrm{SiO}_{x}$ outer-layer of $\sim 5 \mathrm{~nm}$ in thickness. The $0.32 \mathrm{~nm}$ crystalline spacing observed in the inner core of Fe-catalytic SiNWs (upperright inset of Figure 2f) corresponds to the $d$-spacing of Si $\{111\}$ lattice planes. In the Fe-catalytic growth of SiNWs, the Si $\{111\}$ crystalline planes are reported to be most stable. ${ }^{27}$ The ED pattern from the inner core of SiNW (upper-left inset of Figure 2f) indicates that the SiNW has a [11]ㅡ wire growth axis perpendicular to the $(\overline{1} 1 \overline{1})$ lattice planes (Table 1$)$. The wire extruding from the $\mathrm{FeSi}_{2}$-tip and growing along the $\langle 111\rangle$ direction (Figures $2 \mathrm{~d}$ and $2 \mathrm{f}$ ) provides clear evidence for the VLS mechanism in the SiNW synthesis. This result is consistent with previous studies by Wagner ${ }^{39}$ and Lieber and co-workers ${ }^{21}$ that the crystalline growth axis of $\langle 111\rangle$ is most favorable in the metal-catalytic fabrication of SiNWs via VLS processes. The crystalline growth axis, wire growth axis, tip composition, wire crystallization, $\mathrm{Si}$ core diameter, and $\mathrm{SiO}_{x}$ sheath thickness for the $\mathrm{Fe}$ - and $\mathrm{SiO}_{2}$-catalytic SiNWs are listed in Table 1 for comparison.

Catalyses by $\mathrm{Ru}$ and $\mathrm{SiO}_{2}$. We have also synthesized SiNWs with samples of $\mathrm{Si}+\mathrm{SiO}_{2}+\mathrm{RuCl}_{3}(45: 45: 10 \%)$ and $\mathrm{Si}+\mathrm{Ru}$ (90:10\%), respectively, and conveyed the SEM, TEM, HRTEM, ED, and EDS of these fabricated SiNWs in the upper and lower parts of Figure 3. Like what we discussed earlier, when both $\mathrm{RuCl}_{3}$ and $\mathrm{SiO}_{2}$ coexist as catalysts, $\mathrm{SiO}_{2}$ plays a dominant catalytic role over $\mathrm{RuCl}_{3}$ that could partly result from its prevailing abundance in the reacting sample. In general, the $\mathrm{SiNW}$ fabricated from the mixture of $\mathrm{Si}+\mathrm{SiO}_{2}+\mathrm{RuCl}_{3}$ have 10-50 nm diameters, appreciable wire-length, and no apparent metal-tips were found to attach at the ends of SiNWs (Figure $3 a)$. For detailed investigation, the TEM image of the $\mathrm{SiO}_{2}-$ catalytic SiNWs shown in Figure $3 b$ further demonstrates uniformity in the diameters $(12-15 \mathrm{~nm})$ of as-grown SiNWs.

The $\mathrm{SiO}_{2}$-catalytic SiNWs, again, have core-sheath microstructure, as can be seen in HRTEM morphology (Figure 3c), 


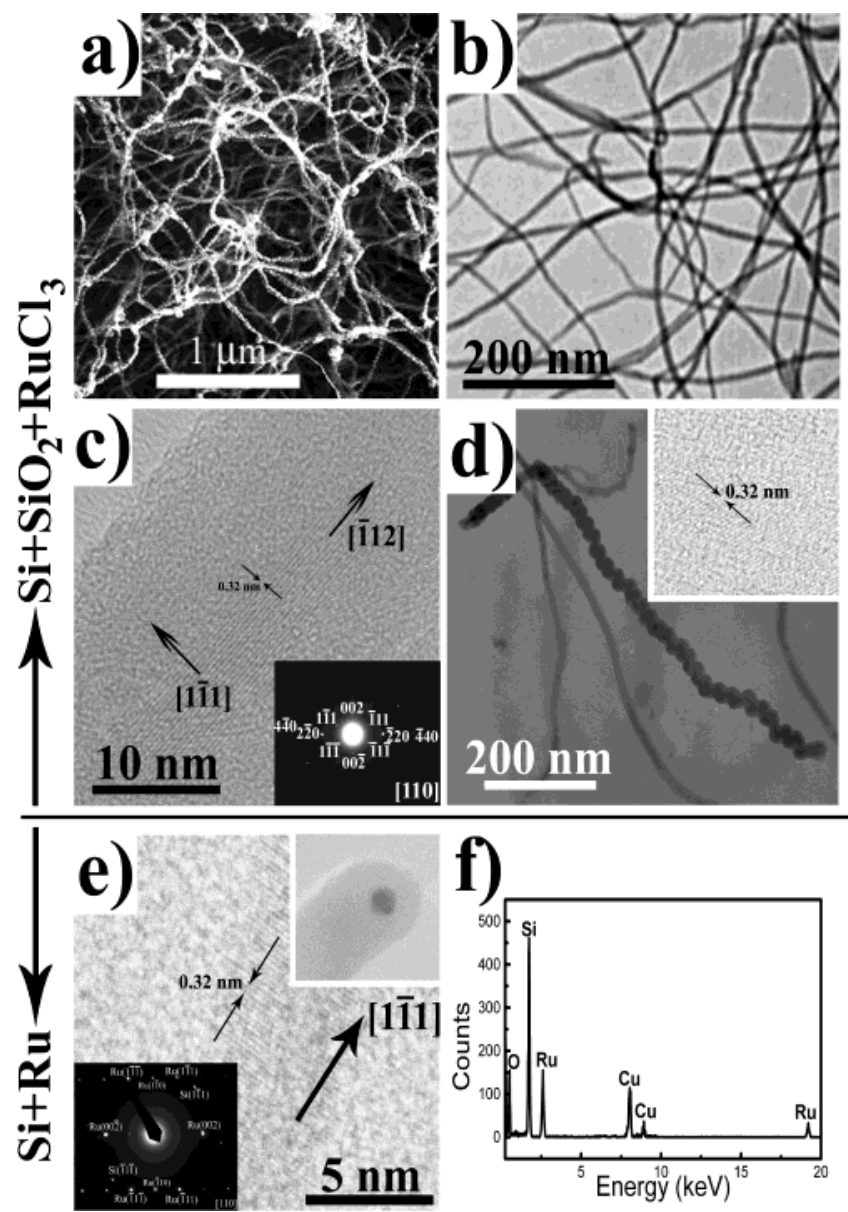

Figure 3. (a) SEM morphology of the SiNWs fabricated from $\mathrm{Si}+$ $\mathrm{SiO}_{2}+\mathrm{RuCl}_{3}$, where the SiNWs have a sharp diameter distribution at $\sim 35 \mathrm{~nm}$ and tens of micrometers in length. (b) TEM morphology of $\mathrm{SiO}_{2}$-catalytic SiNWs with diameters at $12-15 \mathrm{~nm}$. (c) HRTEM image of the $\mathrm{SiO}_{2}$-catalytic $\mathrm{SiNW}$ shows the crystalline $\mathrm{Si}$ core of $\sim 5 \mathrm{~nm}$ diameter, [111] crystalline growth axis with $d$-spacing of $0.32 \mathrm{~nm}$, and [112] wire growth axis. (d) TEM morphology depicts a coil-like SiNW of $\sim 30$ helical pitches, $\sim 30 \mathrm{~nm}$ wire-diameter, $\sim 32 \mathrm{~nm}$ pitch-length, and $\sim 50 \mathrm{~nm}$ coil-diameter. The coiled SiNW is single crystalline with the growing axis normal to the $\mathrm{Si}\{111\}$ lattice planes $(0.32 \mathrm{~nm}$ $d$-spacing in the inset). (e) HRTEM image of a Ru-catalytic SiNW with an ultrathin $\mathrm{Si}$ core of $\sim 5 \mathrm{~nm}$ diameter and a very thick $\mathrm{SiO}_{x}$ amorphous outer-shell (upper-right inset). Crystalline $\mathrm{Si}$ (1111) planes with $0.32 \mathrm{~nm} d$-spacing are perpendicular to the [111] wire growth axis. An ED pattern (lower-left inset), recorded along the [110] zone axis, reveals the crystalline structures of $\mathrm{Si}$ and $\mathrm{Ru}$ for the tip of the wire. (f) EDS spectrum for the tip of the Ru-catalytic SiNW shown in the upper-right inset of 3e. Except for the $\mathrm{O}$ and $\mathrm{Cu}$ signals belonging to the background, the composition of the wire-tip is $\mathrm{RuSi}_{3}$.

where the Si core $(\sim 5 \mathrm{~nm}$ in diameter $)$ is distinctly smaller than the outer amorphous $\mathrm{SiO}_{x}$ sheath $(\sim 10 \mathrm{~nm})$. The small diameter of the $\mathrm{Si}$ core is comparable to those SiNWs fabricated from zeolite. ${ }^{20}$ From the HRTEM in Figure $3 c$, the (11 1 ) lattice fringes with $d$-spacing of $0.32 \mathrm{~nm}$ is observed. The wire growth axis, along the [112] direction, can be identified from the ED pattern as depicted in the inset of Figure 3c. These SiNWs catalyzed by $\mathrm{SiO}_{2}$ have almost no contamination from the metallic catalyst according to EDS analysis (not shown); neither has any metallic tip been found in the wires. This outcome again suggests that $\mathrm{SiO}_{2}$ plays a dominant catalytic role in the growth of $\mathrm{SiNW}$ from $\mathrm{Si}+\mathrm{SiO}_{2}+\mathrm{RuCl}_{3}$ similar to the previous case of $\mathrm{Si}+\mathrm{SiO}_{2}+\mathrm{Fe}$. The fabricated SiNWs also have $\langle 112\rangle$ and $\langle 111\rangle$ wire growth axes at a ratio of $92.3: 7.7 \%$, once more, indicating the competition of catalytic roles between $\mathrm{SiO}_{2}$ and
$\mathrm{RuCl}_{3}$ in the reaction. It is noteworthy that $\mathrm{RuCl}_{3}$ decomposes into $\mathrm{Ru}$ and $\mathrm{Cl}_{2}$ at high temperature, ${ }^{40}$ and the reduced $\mathrm{Ru}$, as a catalyst subsequently, is responsible for the fabricated SiNWs of $\langle 111\rangle$ wire growth axis.

For Ru-catalytic SiNWs, the SEM morphology is quite similar to that of $\mathrm{SiO}_{2}$-catalytic SiNWs (Figure 3a). Figure 3e shows a typical HRTEM image for the wire-body of a Ru-catalytic SiNW with a [11ㅣ] wire growth axis perpendicular to the $\mathrm{Si}(1 \overline{1} 1)$ crystalline planes $(d=0.32 \mathrm{~nm})$. The SiNW contains a metaltip as depicted in the upper-right inset of Figure 3e. The tip is composed of $\mathrm{RuSi}_{3}$ revealed from an EDS measurement (Figure 3f). It is interesting to note that the Ru-catalytic SiNWs contain a heavy amorphous $\mathrm{SiO}_{x}$ outer-shell around the $\mathrm{RuSi}_{3}$-tip. The SiNWs have a very thin crystalline $\mathrm{Si}$ core (only $\sim 5 \mathrm{~nm}$ in diameter) and relatively thick amorphous outer-sheath $(\sim 9 \mathrm{~nm}$ in thickness) (Figure $3 \mathrm{e}$ and Table 1). The thick $\mathrm{SiO}_{x}$ sheath is owing to the higher oxidation potential for $\mathrm{Ru}$ than that for $\mathrm{Si}$ (despite the quite easy oxidation ability for Si itself). ${ }^{41}$ Moreover, an ED pattern for the wire-tip recorded along the [110] zone axis (lower-left inset of Figure 3e) provides information about the tip-composition of $\mathrm{Si}$ and $\mathrm{Ru}$. The growth direction, composition, crystallization, and dimension of $\mathrm{Ru}-$ and $\mathrm{SiO}_{2-}$ catalytic SiNWs are also tabulated in Table 1.

In addition to the filamentary nanowires, some interesting coil-like structure is also present in the products fabricated from $\mathrm{Si}+\mathrm{SiO}_{2}+\mathrm{RuCl}_{3}$ (Figure 3d). The TEM image in Figure 3d shows that the coiled SiNW is of $\sim 30$ helical pitches, $\sim 30 \mathrm{~nm}$ wire-diameter, $\sim 32 \mathrm{~nm}$ pitch-length, and $\sim 50 \mathrm{~nm}$ coil-diameter. From HRTEM (inset of Figure 3d), the coiled SiNW is revealed to be single crystalline with a growing axis normal to the $\mathrm{Si}\{111\}$ lattice planes $(0.32 \mathrm{~nm} d$-spacing). The $\mathrm{Si}$ bonding in the helical SiNWs is an interesting subject to be studied in future. Referring to the very recently discovered bent $\mathrm{Si}=\mathrm{Si}=\mathrm{Si}$ structure in trisilaallene containing a formally $\mathrm{sp}$ hybridized $\mathrm{Si}$ atom, ${ }^{42}$ the structural characterization of $\mathrm{Si}$ atoms in the presently observed helical SiNWs will be very intriguing to be unraveled.

Catalyses by $\mathrm{Pr}$ and $\mathrm{SiO}_{2}$. Microscopic images, ED, and EDS analyses for the SiNWs fabricated from $\mathrm{Si}+\mathrm{SiO}_{2}+\mathrm{Pr}_{6} \mathrm{O}_{11}$ and $\mathrm{Si}+\mathrm{Pr}$ samples are shown in the upper and lower parts of Figure 4, respectively. Once more, the synthesized SiNWs from $\mathrm{Si}+\mathrm{SiO}_{2}+\mathrm{Pr}_{6} \mathrm{O}_{11}$ are catalyzed dominantly by $\mathrm{SiO}_{2}(95.5 \%)$ and lesser by $\operatorname{Pr}_{6} \mathrm{O}_{11}(4.5 \%)$ (Table 1). In addition to the normal SiNWs (SEM morphology in Figure 4a), helical belts (inset of Figure 4a) have also been synthesized from $\mathrm{Si}+\mathrm{SiO}_{2}+\operatorname{Pr}_{6} \mathrm{O}_{11}$. The dimensions for the helical belts are $\sim 60 \mu \mathrm{m}$ pitch-length, $\sim 40 \mu \mathrm{m}$ belt-width, and $\sim 3 \mu \mathrm{m}$ belt-thickness. TEM morphology of the $\mathrm{SiO}_{2}$-catalytic SiNWs (Figure $4 \mathrm{~b}$ ) shows a narrow distribution of wire diameter at $\sim 30 \mathrm{~nm}$. The inset of Figure $4 \mathrm{~b}$ gives a selected-area electron diffraction (SAED) pattern for the SiNW (marked by an arrow in Figure 4b) with the electron beam along the [110] zone axis. While the SAED in Figure 4b shows a single crystallite for the SiNW, plane defects could occasionally be observed in TEM images (not shown). The crystalline structure of SiNWs can further be visualized in the HRTEM image of Figure 4c.

From the HRTEM lattice image of $\mathrm{SiO}_{2}$-catalytic SiNWs (Figure 4c), crystalline Si (1111) planes are observed with $d$-spacing of $0.32 \mathrm{~nm}$, and wire growth axis orients to the [112] direction. Moreover, this SiNW has the crystalline-core and amorphous-sheath structure similar to those SiNWs catalyzed by $\mathrm{SiO}_{2}$ discussed earlier. Analysis for the SAED pattern (inset of Figure 4c), taken from a spot in the wire-core, shows the coexistence of the $\{111\},\{220\}$, and $\{311\}$ lattice plane 


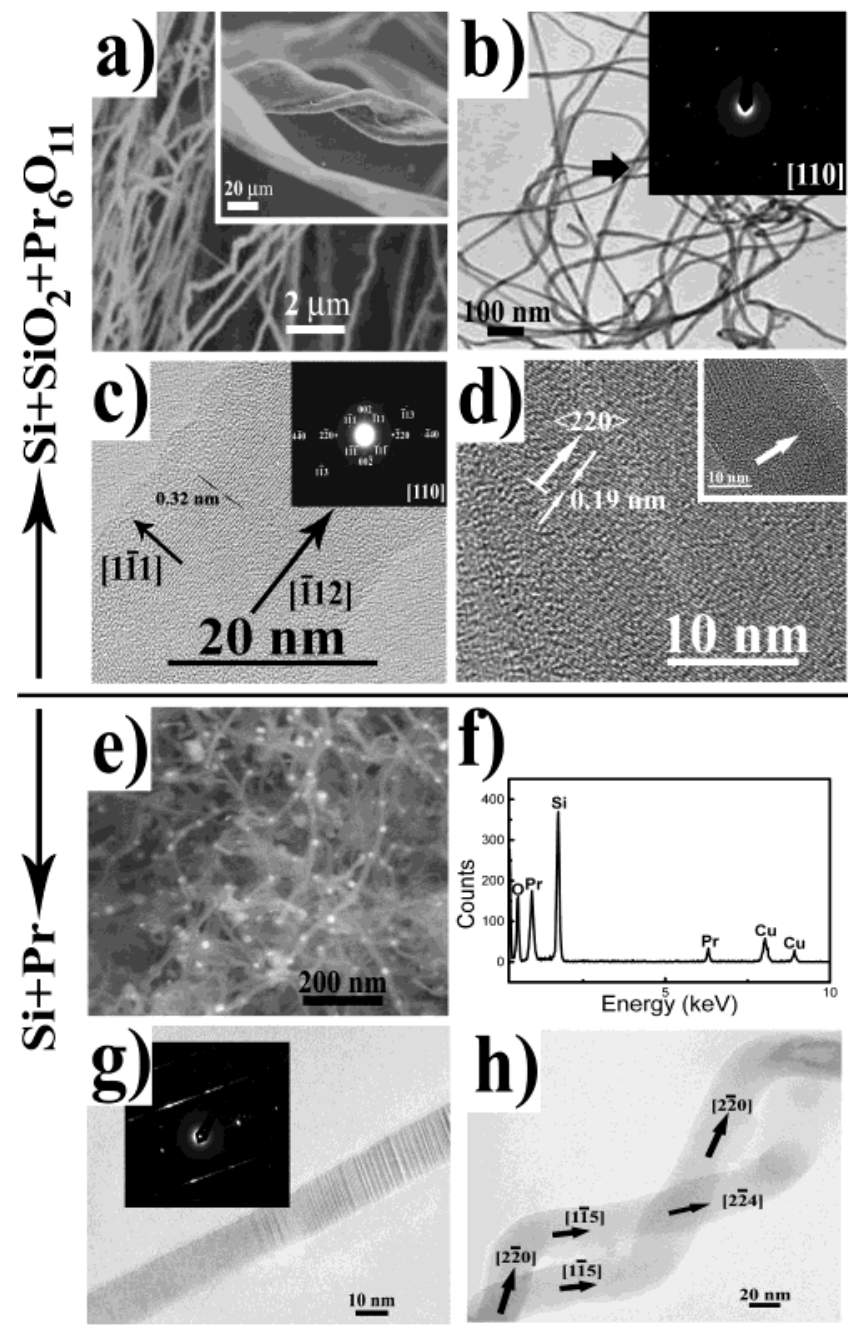

Figure 4. (a) SEM morphology of the SiNWs fabricated from $\mathrm{Si}+$ $\mathrm{SiO}_{2}+\operatorname{Pr}_{6} \mathrm{O}_{11}$, where the diameters of SiNWs are $\sim 20-30 \mu \mathrm{m}$. In addition to the normal SiNWs, helical belts (inset) have also been synthesized with $\sim 60 \mu \mathrm{m}$ pitch-length, $\sim 40 \mu \mathrm{m}$ belt-width, and $\sim 3$ $\mu$ m belt-thickness. (b) TEM morphology of $\mathrm{SiO}_{2}$-catalytic $\mathrm{SiNWs}$ with a uniform diameter of $\sim 30 \mathrm{~nm}$. SAED pattern (inset), recorded along the [110] zone axis, for the SiNW (marked by an arrow) indicates that the SiNW is single crystalline. (c) HRTEM lattice image of $\mathrm{SiO}_{2-}$ catalytic SiNWs shows the crystalline $\mathrm{Si}$ (111) planes with $d$-spacing of $0.32 \mathrm{~nm}$. The [111] crystalline growth axis is perpendicular to the [112] wire growth axis. SAED pattern (inset), taken from a spot in the wire-core, shows the coexistence of the $\{111\},\{220\}$, and $\{311\}$ lattice plane families. (d) $\{220\}$ planes have also been observed in SiNWs with $d$-spacing of $0.19 \mathrm{~nm}$. Defects due to micro-twins exist as well. Arrow in the inset points a twin boundary. (e) Pr-catalytic SiNWs have quite uniform diameters of $\sim 30 \mathrm{~nm}$ and contain metal-tips (white spots) which provide evidence of complying with VLS mechanism in the growing process. (f) EDS spectrum indicates the compositions of $\mathrm{Si}$ body and Pr-tip for the SiNWs except the background of $\mathrm{O}$ and $\mathrm{Cu}$ from the $\mathrm{Cu}$ grid used for SEM measurement. (g) Imperfect packings appear in the TEM of Pr-catalytic SiNWs. ED pattern (inset) shows that the SiNW contains quite a few defects of $\{111\}$ twinnings. (h) TEM morphology of curved SiNWs. The SiNWs change wire-growth directions as indicated, where twinning-defects also show up at the turning sections.

families. This observation was further confirmed by an XRD measurement (not shown). The [1 $\overline{1} 1]$ crystalline growth axis is perpendicular to the [112] wire growth axis as indicated by HRTEM and the ED pattern along the [110] zone axis (Figure $4 c)$.

In addition to the $\mathrm{Si}\{111\}$ crystalline planes, $\{220\}$ planes have also been constructed in SiNWs with $d$-spacing of 0.19 (a)

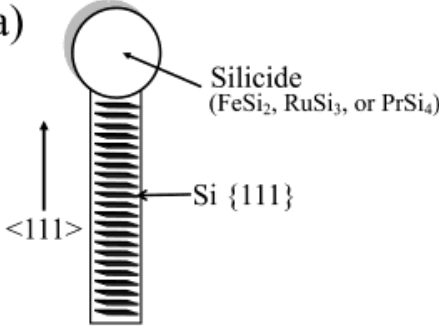

VLS Growth (b)

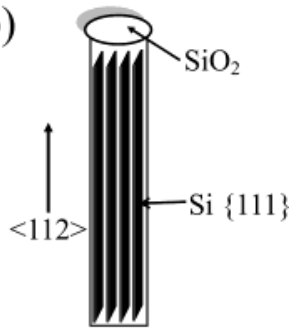

$\mathrm{SiO}_{2}$-catalytic Growth
Figure 5. Schematic for the growth models of metal- and $\mathrm{SiO}_{2}$-catalytic SiNWs.

nm (Figure 4d). Such $\{220\}$ planes, however, appear only occasionally in the crystalline Si cores. Taking a closer look at the magnified HRTEM image (inset of Figure 4d), defects due to micro-twins exist. The micro-twins often locate at the turning section when the growth of SiNW changes direction, consistent with a previous report that micro-twins occur usually in the kinks of SiNWs. ${ }^{30}$

By comparison, the Pr-catalytic SiNWs, as depicted in Figure $4 \mathrm{e}$, are very different in morphology from those catalyzed by $\mathrm{SiO}_{2}$. The Pr-catalytic SiNWs have quite uniform diameters of $\sim 30 \mathrm{~nm}$, and contain metal-tips (white spots in Figure 4e). These metal-tips again provide an evidence of complying with the VLS mechanism in the growing process. The SEM-EDS shown in Figure $4 \mathrm{f}$ indicates the compositions of Si-body and Pr-tip for the SiNWs except the background of $\mathrm{O}$ and $\mathrm{Cu}$ from the $\mathrm{Cu}$ grid used for SEM measurement. The growth direction in the Pr-catalytic SiNWs is the same as those catalyzed by Fe and $\mathrm{Ru}$ that the crystalline growth $\{111\}$ planes are perpendicular to the wire growth axis of $\langle 111\rangle$ as summarized in Table 1.

The twinning-defects, found in the $\mathrm{SiO}_{2}$-catalytic SiNWs (Figure 4d), also appear in Pr-catalytic SiNWs with similar imperfect packings (Figure 4g). The ED pattern in the inset of Figure $4 \mathrm{~g}$ shows that the Pr-catalytic SiNW contains quite a few defects of $\{111\}$ twinning, in accordance with a report that the $\{111\}$ twinning is rather common in the synthesis of $\mathrm{Si}$ nanomaterial. ${ }^{43}$ Curved SiNWs in Figure $4 \mathrm{~h}$ are noteworthy. While the SiNWs change their growth directions (Figure 4h), twinning-defects also show up at the same time. If under an ordered alignment, the curved SiNWs could be a prelude for braided SiNWs, like the braided carbon nanofibers reported previously. ${ }^{44}$

3.2. Growth Mechanisms. In our serial experiments for the formation of SiNWs using only pure metal (Fe, Ru, or Pr) as a catalyst, the growth mechanism that we have observed always follows the VLS process. The synthesized SiNW typically has a metal-tip composed of metal and $\mathrm{Si}$, such as $\mathrm{FeSi}_{2}, \mathrm{RuSi}_{3}$, and $\mathrm{PrSi}_{4}$, respectively. The crystalline growth axis in all cases is along the $\langle 111\rangle$ direction (Table 1); namely, the most stable $\{111\}$ plane is perpendicular to the wire growth $\langle 111\rangle$ axis. A schematic for the orientations representing the crystallite and wire growths via VLS mechanism is illustrated in Figure 5a. This result is consistent with the previous studies by Wagner ${ }^{39}$ and Lieber and co-workers ${ }^{21}$ that a crystalline growth axis of $\langle 111\rangle$ is most favorable in the metal-catalytic fabrications of SiNWs through VLS processes.

In other experiments, we regarded $\mathrm{SiO}_{2}$ as another possible supplying source for $\mathrm{Si}$, thus adding equal weights of $\mathrm{Si}$ and $\mathrm{SiO}_{2}$ as reacting samples in the presence of a small amount of metal catalyst $\left(\mathrm{Si} / \mathrm{SiO}_{2} /\right.$ metal $\left.=45: 45: 10 \%\right)$. From chemical point of view, the reduction of $\mathrm{SiO}_{2}$ as a supplier for $\mathrm{Si}$ can proceed as 


$$
\begin{gathered}
\mathrm{Si}+\mathrm{SiO}_{2} \rightarrow 2 \mathrm{SiO} \\
2 \mathrm{SiO} \rightarrow 2 \mathrm{SiO}_{x}+(1-x) \mathrm{O}_{2} \\
\mathrm{SiO}_{x} \rightarrow \mathrm{Si}_{1-x}+x(\mathrm{SiO}) \\
2 \mathrm{SiO} \rightarrow \mathrm{Si}+\mathrm{SiO}_{2}
\end{gathered}
$$

Wire growth direction in the resultant SiNWs, however, is dramatically dependent on whether $\mathrm{SiO}_{2}$ is included in the reacting sample or not. In all of the cases where $\mathrm{SiO}_{2}$ exists in the reactants, the [1 111$]$ crystalline growth axis in the synthesized SiNWs is perpendicular to the wire axis of [112], i.e., the $\mathrm{Si}$ (11)1) planes are parallel to the wire axis of [112] (Table 1 and Figure $5 b$ ). Besides, the fabricated SiNWs generally have no tips at the wire ends from the reactions containing $\mathrm{SiO}_{2}$, in sharp contrast to those SiNWs synthesized via VLS mechanism without $\mathrm{SiO}_{2}$. Occasionally, beadlike nanoparticles/nanoclusters in $\mathrm{SiNWs}$ were observed in the $\mathrm{SiO}_{2}$-containing synthesis (e.g., Figure 2c). The composition for the beadlike nanostructures, however, is mainly $\mathrm{SiO}_{2}$, opposite to the metal-dominant tips in the SiNWs fabricated without $\mathrm{SiO}_{2}$. Furthermore, the fabrication reaction with $\mathrm{SiO}_{2}$ was observed to be able to proceed at a temperature lower than that only using metal and $\mathrm{Si}$ as reactants.

$\mathrm{SiO}_{2}$ has been argued to play a crucial role in the formation of SiNWs by Lee and co-workers, ${ }^{8,9}$ who have put forward that $\mathrm{SiO}_{2}$, acting as a catalyst, is an enhancement ingredient in the growth mechanism of SiNWs. In our serial attempts to examine the effect of $\mathrm{SiO}_{2}$ on the fabrication of SiNWs, we have also observed the enhancement on the product yield of SiNWs by $\mathrm{SiO}_{2}$. For the wire crystallization in the $\mathrm{SiO}_{2}$-catalytic SiNWs in this work, the observed (111) crystalline planes, parallel to the [112] wire axis, can find support from the study by Dimitriadis et al. ${ }^{45,46}$ In the study of $\mathrm{Si}$ growth on $\mathrm{SiO}_{2}$ substrate by chemical-vapor deposition, Dimitriadis et al. ${ }^{45,46}$ found that an orientation filtering mechanism, due to the growth-velocity competition in the early stage of growth, is responsible for the preferred orientation of Si films. At the experimental condition of high-pressure silane reactant, the grown Si grains exhibit a strong preferred orientation having $\mathrm{Si}\{111\}$ planes perpendicular to the $\mathrm{SiO}_{2}$ substrate, as illustrated symbolically in Figure $5 \mathrm{~b}$. This result agrees with our observation in the present study, i.e., when $\mathrm{SiO}_{2}$ acts as a catalyst in the formation of SiNWs, the $\mathrm{Si}\{111\}$ planes extruding from the $\mathrm{SiO}_{2}$ substrate are perpendicular to the $\mathrm{SiO}_{2}$ surface (Figure $5 \mathrm{~b}$ ).

3.3. Pressure Effect. To study the size dependence of SiNWs on reacting pressure, three pressure sets of Ar carrier gas, 100, 300, and 500 Torr, have been selected in the synthesis of SiNWs from $\mathrm{Si}+\mathrm{SiO}_{2}+\operatorname{Pr}_{6} \mathrm{O}_{11}$. Most of the fabricated nanowires become shorter and wider with increasing Ar carrier pressure as listed in Table 2, indicating while the longitudinal (lengths of SiNWs) growing rate decreases with increasing pressure, the transversal (diameters of SiNWs) one increases.

If under the VLS mechanism, the size of initially formed nanoclusters/nanoparticles is responsible for the diameter of nanowires, such as the $\mathrm{FeSi}_{2}$ liquid-droplet in the Fe-catalytic synthesis of SiNWs. The relation between the diameter of nanoclusters $d$ and the ambient gas pressure $p$ is governed by the inertia fluid model of Yoshida et al., ${ }^{47}$

$$
d \infty p^{n}, \quad n=\frac{1}{3}
$$

From Yoshida's experimental results, they found $n=1 / 2.8$ for
TABLE 2: Size Dependence of SiNWs on the Pressure of Ar Carrier Gas $^{a}$

\begin{tabular}{lccc}
\hline & \multicolumn{3}{c}{ pressure } \\
\cline { 2 - 4 } & 100 Torr & 300 Torr & 500 Torr \\
\hline lengths of SiNWs & tens of $\mu \mathrm{m}$ & several $\mu \mathrm{m}$ & $\begin{array}{c}\text { hundreds of nm } \\
\text { to several } \mu \mathrm{m}\end{array}$ \\
diameters of SiNWs & $10-20 \mathrm{~nm}$ & $\sim 30 \mathrm{~nm}$ & $30-40 \mathrm{~nm}$ \\
${ }^{a}$ Reaction time is $2 \mathrm{~h}$. & &
\end{tabular}

the production of Si nanoparticles by laser ablation with ambient He gas flowing at a constant pressure. Following this model, Zhang et al. ${ }^{33}$ also gave similar Ar pressure effect $(n=1 / 2.5)$ on the growth of SiNWs. Taking our results listed in Table 2 and fitting into eq 2 , the dependence $(n=1 / 1.72)$ of the diameter of SiNWs on the ambient Ar pressure has been determined.

Possible reasons could be found to explain the deviation of our abnormally large $n=1 / 1.72$ value from the inertia fluid model by Yoshida et al. ${ }^{47}$ First, $\mathrm{SiO}_{2}$, rather than the metal catalyst, plays a dominant catalytic role in our experiment for the fabrication of $\mathrm{SiNWs}$ from $\mathrm{Si}+\mathrm{SiO}_{2}+\mathrm{Pr}_{6} \mathrm{O}_{11}$ as discussed in the preceding section. The deviation could stem from a reaction process not complying with the VLS mechanism. Second, a gas-flowing system was employed in our experiment. At higher ambient Ar carrier-gas pressure, the initially formed nanoclusters of $\mathrm{Si}$-grain on $\mathrm{SiO}_{2}$-substrate are subject to more collisions with $\mathrm{Ar}$ atoms, thus slowing down the average driftvelocity of the nanoclusters. Accordingly, the traveling of the nanoclusters takes longer time before their landing on the copper coldfinger or the Si collection-substrate. During this longer period of flight time, bigger sizes of nanoclusters possibly grow, and wider SiNWs are produced consequently.

Meanwhile, the vaporization rate of Si was kept constant under the laser ablation. The absorption/adsorption rate of $\mathrm{Si}$ vapor on the nanoclusters of $\mathrm{Si}$-grain on $\mathrm{SiO}_{2}$-substrate should roughly maintain the same. In a fixed period of time with a constant Si vapor supply, if the SiNW becomes wider, a shorter length of the fabricated SiNW is resulted.

\section{Conclusion}

We have investigated the growths of crystalline SiNWs with the catalyses of pure metals $\left(\mathrm{Fe}, \mathrm{Ru}\right.$, and $\mathrm{Pr}$ ) and $\mathrm{SiO}_{2}$. $\mathrm{Si}\{111\}$ planes have been found to be most stable in these catalytic fabrications. While the wire growth axis is along $\langle 111\rangle$ for the metal-catalytic SiNWs complying with VLS mechanism, the wire growth axis directs to $\langle 112\rangle$ in the SiNWs catalyzed by $\mathrm{SiO}_{2}$. Different growth mechanisms for metal- and $\mathrm{SiO}_{2}$-catalytic syntheses of SiNWs have been discussed. Pressure effect on the growing process has been examined. Possible reasons have been provided to explain the observations.

Acknowledgment. The SEM, TEM, HRTEM, ED, SAED, and EDS measurements for this study in Instrumentation Center of National Taiwan University and Instrumentation Center of National Tsing-Hua University, both sponsored by National Science Council of ROC, are acknowledged. This work is supported by CTCI Foundation and National Science Council of ROC (Grant Nos. 91-2113-M-002-035 and 91-2120-M-002001).

\section{References and Notes}

(1) Alivisatos, A. P. Science 1996, 271, 933.

(2) Baron, T.; Martin, F.; Mur, P.; Wyon, C.; Dupuy, M.; Busseret, C.; Souifi, A.; Guillot, G. Appl. Surf. Sci. 2000, 164, 29. 
(3) Park, N.-M.; Kim, S. H.; Sung, G. Y.; Park, S.-J. Chem. Vap. Deposition 2000, 8, 254.

(4) Liu, H. I.; Biegeisen, D. K.; Ponce, F. A.; Johnson, N. M.; Pease, R. F. W. Appl. Phys. Lett. 1994, 64, 1383.

(5) Wakayama, Y.; Tanaka, S. J. Cryst. Growth 1997, 181, 304.

(6) Ono, T.; Saitoh, H.; Esashi, M. Appl. Phys. Lett. 1997, 70, 1852.

(7) Sanders, G. D.; Chang, Y. C. Phys. Rev. B 1992, 45, 9202.

(8) Wang, N.; Zhang, Y. F.; Tang, Y. H.; Lee, C. S.; Lee, S. T. Appl. Phys. Lett. 1998, 73, 3902.

(9) Wang, N.; Tang, Y. H.; Zhang, Y. F.; Lee, C. S.; Lee, S. T. Phys. Rev. B 1998, 58, 16024.

(10) Wang, N.; Tang, Y. H.; Zhang, Y. F.; Lee, C. S.; Bello, I.; Lee, S.

T. Chem. Phys. Lett. 1999, 299, 237.

(11) Tang, Y. H.; Zheng, Y. F.; Lee, C. S.; Lee, S. T. Chem. Phys. Lett. 2000, 328, 346.

(12) Zhang, Y. F.; Tang, Y. H.; Wang, N.; Yu, D. P.; Lee, C. S.; Bello, I.; Lee, S. T. Appl. Phys. Lett. 1998, 72, 1835.

(13) Wang, N.; Tang, Y. H.; Zhang, Y. F.; Yu, D. P.; Lee, C. S.; Bello,

I.; Lee, S. T. Chem. Phys. Lett. 1998, 283, 368.

(14) Zhang, Y. F.; Tang, Y. H.; Wang, N.; Lee, C. S.; Bello, I.; Lee, S. T. J. Cryst. Growth 1999, 197, 136.

(15) Tang, Y. H.; Zhang, Y. F.; Wang, N.; Shi, W. S.; Lee, C. S.; Bello,

I.; Lee, S. T. J. Vac. Sci. Technol. B 2001, 19, 317.

(16) Lee, S. T.; Zhang, Y. F.; Wang, N.; Tang, Y. H.; Bello, I.; Lee, C. S.; Chung, Y. W. J. Mater. Res. 1999, 14, 4503

(17) Fan, X. H.; Xu, L.; Li, C. P.; Zheng, Y. F.; Lee, C. S.; Lee, S. T. Chem. Phys. Lett. 2001, 334, 229.

(18) Shi, W. S.; Peng, H. Y.; Zheng, Y. F.; Wang, N.; Shang, N. G.; Pan, Z. W.; Lee, C. S.; Lee, S. T. Adv. Mater. 2000, 12, 1343.

(19) Zhang, Y. F.; Tang, Y. H.; Lam, C.; Wang, N.; Lee, C. S.; Bello, I.; Lee, S. T. J. Cryst. Growth 2000, 212, 115

(20) Li, C. P.; Sun, X. H.; Wong, N. B.; Lee, C. S.; Lee, S. T.; Teo, B.

K. Chem. Phys. Lett. 2002, 365, 22.

(21) Morales, A. M.; Lieber, C. M. Science 1998, 279, 208.

(22) Hu, J.; Odom, T. W.; Lieber, C. M. Acc. Chem. Res. 1999, 32, 435.

(23) Duan, X.; Lieber, C. M. J. Am. Chem. Soc. 2000, 122, 188

(24) Cui, Y.; Leiber, C. M. Science 2001, 291, 851. 48 .

(25) Hu, J.; Ouyang, M.; Yang, P.; Lieber, C. M. Nature 1999, 399

(26) Cui, Y.; Lauhon, L. J.; Gudiksen, M. S.; Wang, J.; Lieber, C. M. Appl. Phys. Lett. 2001, 78, 2214.
(27) Yu, D. P.; Lee, C. S.; Bello, I.; Sun, X. S.; Tang, Y. H.; Zhou, G. W.; Bai, Z. G.; Feng, S. Q. Solid State Commun. 1998, 105, 403.

(28) Yu, D. P.; Bai, Z. G.; Ding, Y.; Hang, Q. L.; Zhang, H. Z.; Wang, J. J.; Zou, Y. H.; Qian, W.; Xiong, G. C.; Zhou, H. T.; Feng, S. Q. Appl. Phys. Lett. 1998, 72, 3458

(29) Feng, S. Q.; Yu, D. P.; Zhang, H. Z.; Bai, Z. G.; Ding, Y. J. Cryst Growth 2000, 209, 513.

(30) Zhou, G.; Zhang, Z.; Yu, D. P. J. Cryst. Growth 1999, 197, 129

(31) Yu, D. P.; Bai, Z. G.; Wang, J. J.; Zou, Y. H.; Qian, W.; Fu, J. S.; Zhang, H. Z.; Ding, Y.; Xiong, G. C.; You, L. P.; Xu, J.; Feng, S. Q. Phys. Rev. B 1999, 59, 2498.

(32) Zhou, G. W.; Zhang, Z.; Bai, Z. G.; Feng, S. Q.; Yu, D. P. Appl. Phys. Lett. 1998, 73, 677.

(33) Zhang, H. Z.; Yu, D. P.; Ding, Y.; Bai, Z. G.; Hang, Q. L.; Feng, S. Q. Appl. Phys. Lett. 1998, 73, 3396

(34) Bai, Z. G.; Yu, D. P.; Wang, J. J.; Zou, Y. H.; Qian, W.; Fu, J. S.; Feng, S. Q.; Xu, J.; Lou, L. P. Mater. Sci. Eng. B 2000, 72, 117. (35)

(36) Xing, Y. J.; Xi, Z. H.; Yu, D. P.; Hang, Q. L.; Yan, H. F.; Feng,

S. Q.; Xue, Z. Q. Chin. Phys. Lett. 2002, 19, 240.

(37) Yan, H. F.; Xing, Y. J.; Hang, Q. L.; Yu, D. P.; Wang, Y. P.; Xu,

J.; Xi, Z. H.; Feng, S. Q. Chem. Phys. Lett. 2000, 323, 224.

(38) Wagner, R. S.; Ellis W. C. Appl. Phys. Lett. 1964, 4, 89.

(39) In Whisker Technology; Levitt, A. P., Ed.; Wiley-Interscience: New York, 1970; pp 47-119.

(40) Seddon, E. A.; Seddon, K. R. The Chemistry of Ruthenium; Elsevier: Amsterdam, 1984

(41) Harris, D. C. Quantitative Chemical Analysis, 4th ed.; W. H. Freeman and Company: New York, 1995.

(42) Ishida, S.; Iwamoto, Y.; Kabuto, C.; Kira, M. Nature 2003, 421, 725

(43) Ma, X. L.; Zhu, Y. L.; Zhang, Z. Philos. Mag. Lett. 2002, 82, 461.

(44) Boehm, H. P. Carbon 1973, 11, 583.

(45) Dimitriadis, C. A.; Stoemenos, J.; Coxon, P. A.; Friligkos, S.; Antonopoulos, J.; Economou, N. A. J. Appl. Phys. 1993, 73, 8402.

(46) In Silicon-Based Materials and Devices; Nalwa, H. S., Ed.; Academic Press: San Diego, 2001; Vol. 2, pp 193-223.

(47) Yoshida, T.; Takeyama, S.; Yamada, Y.; Mutoh, K. Appl. Phys. Lett. 1996, 68, 1772. 